Z. Klin. Chem. Klin. Biochem.

12. Jg. 1974, S. $287-293$

\title{
Die Messung der Spurenelemente Chrom und Mangan im Serum mittels flammenloser Atom- absorption ${ }^{1)}$
}

Von B. Grafflage, G. Buttgereit, W. Kübler und H.-M. Mertens

Aus der 1. Medizinischen Klinik B (Direktor: Prof. Dr. F. Loogen) der Universität Düsseldorf und dem OrganischAnalytischen Laboratorium der Bayer AG, Leverkusen

(Eingegangen am 22. November 1973/19. Februar 1974)

Es wird eine einfache Methode zur Messung des Chrom- und Mangan-Gehaltes im menschlichen Serum mittels flammemloser Atomabsorption beschrieben.

Mögliche Fehlerquellen des Verfahrens werden aufgezeigt.

Bei 50 anscheinend gesunden Personen wird mit dieser Methode der Chrom- und Mangan-Gehalt im Serum bestimmt. Für beide Elemente fand sich eine log-normale Verteilung mit einem Median von 0,60 $\mu \mathrm{g} / \mathrm{l}$ für Chrom (arithmetischer Mittelwert: $0,73 \mu \mathrm{g} / \mathrm{l}$ ) und

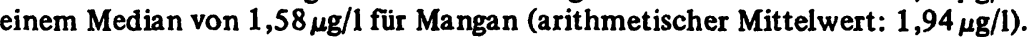

\section{Determination of the trace elements chromium and manganese in serum by flameless atomic absorption}

A simple method is described for the measurement of the concentration of chromium and manganese in serum with the aid of flameless atomic absorption. Possible sources of error in the method are shown. Using this method, the concentrations of chromium and manganese were measured in the sera of 50 apparently healthy persons. Both elements showed a normal log distribution with a median of $0.60 \mu \mathrm{g} / \mathrm{l}$ for chromium (arithmetic average, $0.73 \mu \mathrm{g} / \mathrm{l}$ ) and a median of $1.58 \mu \mathrm{g} / \mathrm{l}$ for manganese (arithmetic average, $1.94 \mu \mathrm{g} / \mathrm{l}$ ).

Die physiologische und klinische Bedeutung von Spurenelementen ist noch weitgehend unbekannt. Dies ist vor allem auf methodische Schwierigkeiten zurückzuführen. Die bisher für die Bestimmung von Spurenelementen in biologischen Geweben angewendeten Verfahren sind für die Klinik entweder zu teuer und zu aufwendig - wie die Neutronenaktivierungsanalyse - oder sie weisen eine zu große methodische Fehlerbreite bei relativ geringer Nachweisgrenze auf; dies gilt sowohl für die Anwendung der Flammenatomabsorption oder der Emissionsspektralanalyse nach vorheriger Anreicherung der Elemente durch Komplexierung und Fällung bzw. Veraschung, als auch für die spektrometrischen, kolorimetrischen und fluorometrischen Verfahren. Mit der flammenlosen Atomabsorptionsspektroskopie $(1,2)$ wurde ein neues Verfahren entwickelt, das furr die Messung von Spurenelementen in der Klinik geeignet erscheint. Diese Methode weist als Vorteil einen sehr einfachen und kurzen Analysengang bei relativ hoher Empfindlichkeit und Nachweisgrenze auf, so daß in wäßriger Lösung die Messung von Spurenelementen in den im Serum zu erwartenden Konzentrationen problemlos gelingt. Bei Verwendung von biologischem Material fuhhren jedoch die in der Probe vorhandenen organischen und anorganischen Substanzen zu er-

1) Die Untersuchungen wurden mit Unterstützung der Deutschen Forschungsgemeinschaft im Rahmen des SFB 30 (Kardiologie) der Universität Düsseldorf durchgeführt. heblichen Störeffekten, die sich in unspezifischen Signalen und in Veränderungen des spezifischen Signales äußern können.

Im folgenden soll eine Methode zur Messung von Chrom und Mangan im Serum des Menschen mittels flammenloser Atomabsorption beschrieben und begründet werden.

\section{Material und Methoden}

\section{Gewinnung der Serumproben}

Das Blut wurde von gesunden Versuchspersonen durch Venenpunktion gewonnen. Um den Kontakt der Blutprobe mit einer Metallkanüle zu vermeiden, wurde eine Braunüle ${ }^{2}$ ) verwendet. Nach etwa einer Stunde wurde der Blutkuchen durch zehn Minuten langes Zentrifugieren bei $2.500 \mathrm{~g}$ vom Serum getrennt. Um eine Adsorption der in geringer Menge im Serum vorliegenden Spurenelemente an Glaswände zu vermeiden, wurden bei der $\mathrm{Ge}-$ winnung und Aufbereitung der Blutproben nur Plastikgefäße (Polypropylen) und Eppendorf-Pipetten ${ }^{3}$ ) (mit Plastikspitzen) verwendet.

\section{Geräte}

Die Messungen wurden zunächst mit einem Atomabsorptionsgerät ohne Deuteriumkompensator $\left.(290 \mathrm{AAS})^{4}\right)$ in Kombination mit einer spannungsgesteuerten Graphitrohrküvette ohne Mög-

2) Braunüle der Firma Braun, Melsungen

3) Eppendorf-Pipetten der Firma Eppendorf, Hamburg

4) Atomabsorptions-Gerät 290 der Bodenseewerke Perkin-Elmer, Überlingen 
lichkeit der kontinuierlichen Aufheizung (HGA 70) ${ }^{5}$ ) durchgefuihrt.

Die weiteren Versuche wurden mit Atomabsorptionsgeräten mit Deuteriumkompensator vorgenommen, wobei vergleichend an einem Ein-Strahl-(300 S AAS $\left.)^{6}\right)$ und an einem Zwei-Strahl-Gerät (403 AAS) ${ }^{7}$ ) gemessen wurde. Als Graphitrohrküvette wurde zusätzlich zur HGA $70^{5}$ ) ein stromgesteuertes Gerät mit Temperaturprogramm (HGA 72) ${ }^{8}$ ) verwendet.

Die Auswertung der registrierten Kurven erfolgt von der Basislinie bei Beginn der Atomisierung bis zum Maximalwert. Die mit diesem linearen Auswertverfahren ermittelten Ergebnisse stimmen mit den bei integraler Auswertung gemessenen Werten gut überein und zeigen keine systematische Abweichung $(2)^{9}$ )

Chemikalien

Die verwendeten Chemikalien wurden alle von der Firma Merck, Darmstadt bezogen. Sie wiesen die Reinheitsgrade "Suprapur" oder ,pro analysi“" auf (siehe Ergebnisse).

5) Graphitrohrküvette HGA 70 der Bodenseewerke PerkinElmer

6) Atomabsorptions-Gerät $300 \mathrm{~S}$ der Bodenseewerke PerkinElmer

7) Atomabsorptions-Gerät 403 der Bodenseewerke Perkin-Elmer

8) Graphitrohrküvette HGA 72 der Bodenseewerke Perkin-Elmer

$\left.{ }^{9}\right)$ unveröffentlichte Berichte

\section{Ergebnisse}

Verwendung des Gerätes 290 AAS in Kombination mit der Graphitroh rküvette HGA 70

Bei Verwendung dieser Gerätekombination ergab die Messung von Chrom im Serum nach den ursprünglich von der Herstellerfirma empfohlenen Verfahren keine reproduzierbaren Werte (siehe Tab. 1, Versuchsansatż 1).

Da mit dieser Methode auch unspezifische Rauchsignale erfaßt wurden, lagen die von uns gemessenen Werte für den Chromgehalt im Serum mit Mittelwerten von $28 \mu \mathrm{g} / 1$ deutlich höher als die mittels Neutronenaktivierung ermittelten Normwerte von $9 \mu \mathrm{g} / 1$ (3). In weiteren Voruntersuchungen wurde deshalb zunächst versucht, durch Vorbereitung der Serumproben die störende Matrix zu entfernen und die Spurenelemente anzureichern. Die angewendeten Verfahren sind in Tabelle 1 zusammengefaßt. Mit keiner Methode konnten brauchbare Ergebnisse erzielt werden.

Tab. 1. Voruntersuchungen zum Nachweis von Chrom und Mangan mittels flammenloser Atomabsorption (AAS) in Verbindung mit dem Gerät AAS 290 und der Graphitrohrküvette HGA 70 (*nach Zugabe von $20 \mu$ jeweils ein Trocknungsschritt)

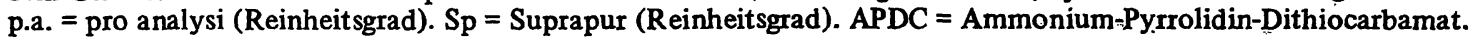
MIBK = Methyl-Isobutylketon

\begin{tabular}{|c|c|c|c|c|c|c|c|c|}
\hline & & \multicolumn{7}{|c|}{ Versuchsansätze } \\
\hline & & 1 & 2 & 3 & 4 & 5 & 6 & 7 \\
\hline \multirow{4}{*}{ 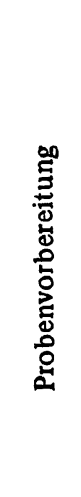 } & Serum $[\mathrm{ml}]$ & $<2 \mathrm{ml}$ & $1 \mathrm{ml}$ & $1 \mathrm{ml}$ & $1 \mathrm{ml}$ & $5 \mathrm{ml}$ & $5 \mathrm{ml}$ & $5 \mathrm{ml}$ \\
\hline & Proteinfällung & & $\begin{array}{l}+1 \mathrm{ml} \\
1 \mathrm{~mol} / 1 \\
\mathrm{H}_{2} \mathrm{SO}_{4} \\
\text { p.a. }\end{array}$ & $\begin{array}{l}+1 \mathrm{ml} \\
20 \% \\
\mathrm{CCl}_{3} \mathrm{COOH} \\
\text { p.a. }\end{array}$ & $\begin{array}{l}\text { Verdünnung } \\
+1 \mathrm{ml} \\
\text { demin. } \\
\text { Wasser }\end{array}$ & $\begin{array}{c}+2,5 \mathrm{ml} \\
\text { konz. } \mathrm{HCl} \\
\text { Sp. }\end{array}$ & $\begin{array}{c}+2,5 \mathrm{ml} \\
20 \% \\
\mathrm{CCl}_{3} \mathrm{COOH} \\
\text { p.a. }\end{array}$ & $\begin{array}{c}+2,5 \mathrm{ml} \\
20 \% \\
\mathrm{CCl}_{3} \mathrm{COOH} \\
\text { p.a. }\end{array}$ \\
\hline & Einengung & & & & & $\begin{array}{l}5 \mathrm{ml} \\
\text { Überstand } \\
\text { bei } 200^{\circ} \mathrm{C}\end{array}$ & $\begin{array}{l}\quad 5 \mathrm{ml} \\
\text { Überstand } \\
\text { bei } 160^{\circ} \mathrm{C}\end{array}$ & $\begin{array}{l}5 \mathrm{ml} \\
\text { Überstand } \\
\text { bei } 160^{\circ} \mathrm{C}\end{array}$ \\
\hline & $\begin{array}{l}\text { Rückstand: } \\
\text { Aufnahme in }\end{array}$ & & & & & $\begin{array}{l}\text { 0,5 ml konz. } \\
\text { HCl Sp. }\end{array}$ & $\begin{array}{c}0,15 \mathrm{ml} \text { Phthal- } \\
\text { säure }+0,1 \mathrm{ml} \\
\text { APDC }\end{array}$ & $\begin{array}{l}1 \mathrm{ml} \text { APDC + } 1 \text { ml Phthal- } \\
\text { säure }+3 \mathrm{ml} \text { MÎBK } \rightarrow \\
\text { schütteln } \rightarrow \text { zentrifugieren } \\
\rightarrow \text { organ. Phase messen }\end{array}$ \\
\hline \multicolumn{2}{|c|}{ Probenvolumen } & $20 \mu \mathrm{l}$ & $50 \mu 1$ & $4 \times 20 \mu \mathrm{l} *$ & 20 u. $50 \mu 1$ & $20 \mu \mathrm{l}$ & $20 \mu l$ & $20 \mu \mathrm{l}$ \\
\hline \multirow{5}{*}{ 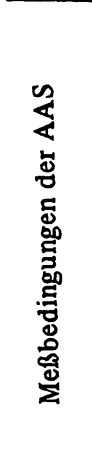 } & Programmwahl & $7\left(1100^{\circ} \mathrm{C}\right)$ & $6\left(750^{\circ} \mathrm{C}\right)$ & 7 & 7 & 7 & 7 & 6 \\
\hline & $\begin{array}{l}\text { Atomisierungs- } \\
\text { Spannung [V] }\end{array}$ & 9 & 9 & 9 & 9 & 9 & 9 & 9 \\
\hline & $\begin{array}{l}\text { Trocknungs- } \\
\text { zeit [s] }\end{array}$ & 60 & 120 & 120 & 60 & 40 & 40 & 40 \\
\hline & $\begin{array}{l}\text { Veraschungs- } \\
\text { zeit [s] }\end{array}$ & 300 & 300 & 300 & 300 & 120 & 120 & 30 \\
\hline & $\begin{array}{l}\text { Atomisierungs- } \\
\text { zeit [s] }\end{array}$ & 20 & 20 & 20 & 10 & 10 & 10 & 10 \\
\hline \multicolumn{2}{|c|}{ Ergebnis } & $\begin{array}{l}\text { Unspezifi- } \\
\text { sches Rauch- } \\
\text { signal }\end{array}$ & $\begin{array}{l}\text { Unspezifi- } \\
\text { sches Rauch- } \\
\text { signal }\end{array}$ & $\begin{array}{l}\text { Unspezifi- } \\
\text { sches Rauch- } \\
\text { signal }\end{array}$ & $\begin{array}{l}\text { Unspezifi- } \\
\text { sches Rauch- } \\
\text { signal }\end{array}$ & $\begin{array}{l}\text { Unnspezifi- } \\
\text { sches Rauch- } \\
\text { signal }\end{array}$ & $\begin{array}{l}\text { Unspezifi- } \\
\text { sches Rauuch- } \\
\text { signal }\end{array}$ & $\begin{array}{l}\text { Unspezifi- } \\
\text { sches Rauch- } \\
\text { signal }\end{array}$ \\
\hline
\end{tabular}


Die Verwendung des Gerätes $300 \mathrm{~S}$ AAS bzw. $403 \mathrm{AAS}$ in Kombination mit der Graphitrohrküvette HGA 70 bzw. HGA 72 und dem Deuteriumkompensator

\section{Die Messung von Chrom (Cr) im Serum}

Die Bedingungen fuir die Messung von Chrom im Serum sind in Tabelle 2 aufgefuhrt. In Folge des geringen Chromgehaltes im Serum und der geringeren Empfindlichkeit der Chrom-Linie empfiehlt es sich, für den Meßvorgang ein größeres Volumen von $50 \mu l$ Serum einzusetzen. Da Serum unmittelbar fur die Messung verwendet wird, muß die organische und anorganische Matrix bei der Veraschung vollständig entfernt werden.

Tab. 2. Vorschrift für die flammenlose Atomabsorption

\section{Element: Chrom}

Matrix: Serum

1. Probenvorbehandlung: keine (Verwendung von Serum)

2. Geräte: $\mathbf{4 0 3}$ AAS oder 300 S AAS ohne Deuteriumkompensator

2.1. Einstellungen : 403 AAS bzw. $300 \mathrm{~S}$ AAS

Wellenlänge $\quad: 357,9 \mathrm{~nm}$

HKL : PE Intensitron

Lampenstrom : $25 \mathrm{mAmpere}$

für 403 AAS

Absorbance : 0,5 Ampere

Dämpfung : 1 (gilt auch für $300 \mathrm{~S}$ AAS)

2.2. Einstellungen : Graphitrohrküvette HGA 72

$\begin{array}{llll}\text { Stufe I } & \text { : Trocknung } 1 & 60 \mathrm{~s} & 82^{\circ} \mathrm{C}\end{array}$ Stufe II : Trocknung $2 \quad 60 \mathrm{~s} \quad 118^{\circ} \mathrm{C}$

Temperaturprogramm Rate 5, kontinuierlicher Temperaturanstieg bis $1020^{\circ} \mathrm{C}$ (Vorveraschung)

Stufe III $\quad$ : Endveraschung $90 \mathrm{~s} \quad 1400^{\circ} \mathrm{C}$

Stufe IV : Atomisierung $20 \mathrm{~s} \quad 2474^{\circ} \mathrm{C}$

2.3. Einstellungen : Schreiber

5 mVolt : Vollausschlag

Papiervorschub : $5 \mathrm{~s} / \mathrm{cm}$

3. Pipettiervolumen : $50 \mu \mathrm{l}$ Serum

4. Nachweisgrenze : $12,5 \mathrm{pg}(50 \mu \mathrm{l}$ einer Probe mit $0,25 \mu \mathrm{g} / \mathrm{l})$

5. Auswertung

Die Auswertung erfolgt von der Basislinie bei Atomisierungsbeginn bis zum Maximalwert. Eine zu starke Basisverschiebung während der Atomisierung wird durch eine Pappblende vor dem rechten Küvettenfenster vermieden.

6. Eichung

Die Eichung erfolgt durch Aufstockung der Serumprobe mit Chromkonzentrationen, die im Bereich der zu erwartenden Serumkonzentration liegen. Dabei soll das Serum höchstens um $10 \%$ verdünnt werden.

Empfohlene Eichwerte: 10,5 und $1 \mu \mathrm{g} / 1 \mathrm{Chrom}$

Abbildung 1 zeigt die Optimierung der Veraschungstemperatur für den Nachweis von Chrom im Serum. Bei einer Temperatur von $1400^{\circ} \mathrm{C}$ sind keine unspezifischen Signale mehr nachweisbar. Dadurch kann auf die Anwendung des die Empfindlichkeit des Meßssystems reduzierenden Deuteriumkompensators zur Unterdrückung unspezifischer Signale verzichtet und die Nachweisgrenze für Chrom im Serum verbessert werden.
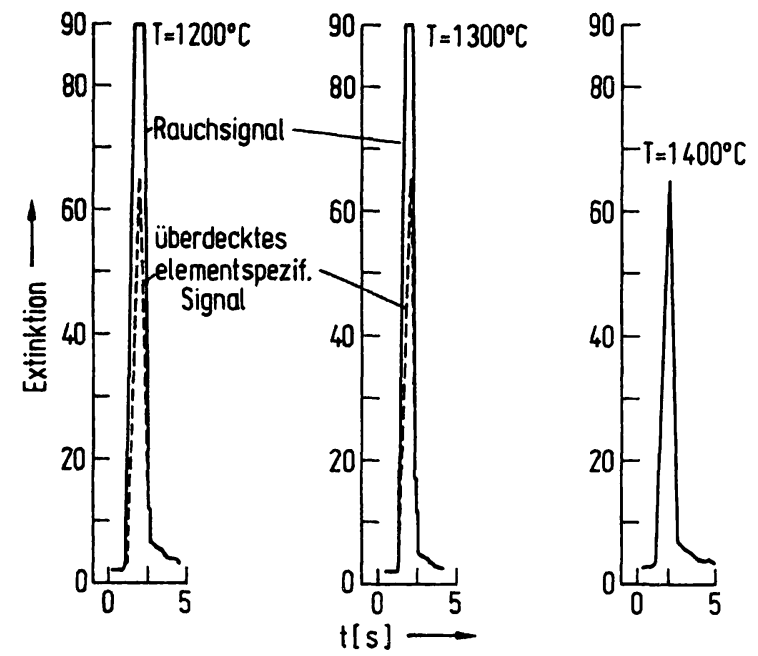

Abb. 1. Die Optimierung der Veraschungstemperatur für den Nachweis von Chrom im Serum mittels flammenlose Atomabsorptionsspektroskopie

Auf der Ordinate ist die Extinktion in willkürlichen Einheiten, auf der Abszisse die Zeit wiedergegeben. Die bei verschiedenen Veraschungstemperaturen erhaltenen Signale sind durch ausgezogene Linien, bei $1200^{\circ} \mathrm{C}$ und $1300^{\circ} \mathrm{C}$ das durch Rauch überlagerte elementspezifische Signal durch gestrichelte Linien gekennzeichnet.

Das Vorgehen entspricht den in Tabelle 2 gemachten Angaben, mit Ausnahme der Variation der Veraschungstemperatur von $1200^{\circ} \mathrm{C}-1400^{\circ} \mathrm{C}$.

Aus der Abbildung geht hervor, daß bei Veraschungstemperaturen von $1200^{\circ} \mathrm{C}-1300^{\circ} \mathrm{C}$ unspezifische Rauchsignale das elementspezifische Signal verdecken, das erst bei einer Veraschungstemperatur von $1400^{\circ} \mathrm{C}$ selektiv nachweisbar ist.
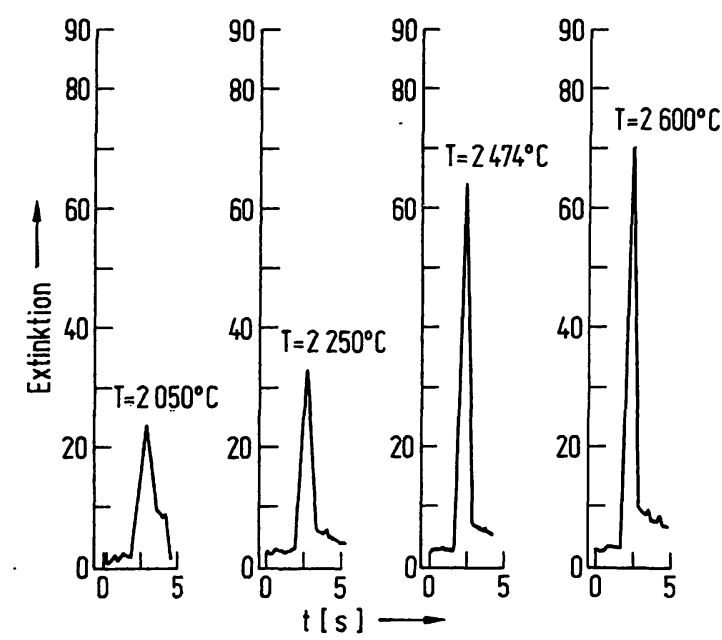

Abb. 2. Die Optimierung der Atomisierungstemperatur für den Nachweis von Chrom im Serum mittels flammenloser Atomabsorptionsspektroskopie

Auf der Ordinate ist die Extinktion in willkürlichen Einheiten, auf der Abszisse die Zeit wiedergegeben.

Das Vorgehen entspricht den in Tabelle 2 gemachten Angaben, mit Ausnahme der Atomisierungstemperatur. Mit zunehmender Temperatur ergeben sich höhere elementspezifische Extinktionswerte. Der günstigste Meßbereich dürfte bei einer Temperatur von $2474^{\circ} \mathrm{C}$ erreicht sein (s. auch Text). 


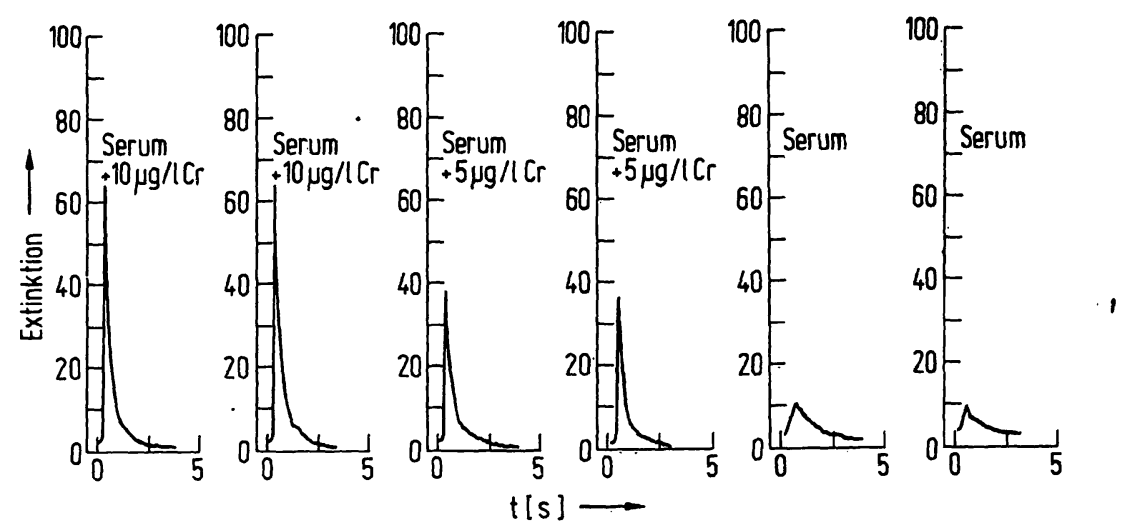

Abb. 3. Originalregistrierungen von Chrom im Serum, sowie von aufgestocktem Serum

Auf der Ordinate ist die Extinktion in willkürlichen Einheiten, auf der Abszisse die Zeit wiedergegeben.

Die Versuchsbedingungen sind in Tabelle 2 angegeben.

Es sind jeweils Doppelbestimmungen angegeben. Von links nach rechts sind aufgezeichnet:

1. Doppelbestimmung mit $10 \mu \mathrm{g} / \mathrm{l}$ Chrom aufgestocktes Serum

2. Doppelbestimmung mit $5 \mu \mathrm{g} / \mathrm{l}$ aufgestocktes Serum

3. Doppelbestimmung: Messung des Chromgehaltes im Nativserum

Von der Extinktion (in Skalenteilen) der aufgestockten Seren ist die Extinktion der Originalprobe zu subtrahieren, um die Extinktion für $10 \mathrm{bzw} .5 \mu \mathrm{g} / \mathrm{l}$ Chrom zu erhalten.

Abbildung 2 zeigt den Nachweis von Chrom im Serum in Abhängigkeit von der Atomisierungstemperatur. Die günstigsten Meßbedingungen dürften bei einer Atomisienungstemperatur von $2474^{\circ} \mathrm{C}$ erreicht sein, da bei einer geringeren Atomisierungstemperatur die Nachweisgrenze ungünstiger wird. Bei einer Temperatur über $2474^{\circ} \mathrm{C}$ nimmt als Nachteil die Eigenemission der Graphitrohrküvette deutlich zu, so daß keine Nullinienkonstanz mehr gegeben ist. Bei einer Atomisierungstemperatur von $2474^{\circ} \mathrm{C}$ läßt sich die Eigenemission des Graphitrohrs durch Vorschalten einer Lochblende weitgehend eliminieren.

Die mit der Atomabsorption erzielten Ergebnisse müssen auf Eichwerte bezogen werden. Diese werden durch Aufstockung von Serum mit Lösungen bekannten Chromgehal tes hergestellt; dabei sollte die Verdünnung des Serums höchstens $10 \%$ ausmachen.

Abbildung 3 zeigt eine Original registrierung für die Messung von Chrom im Serum. Es sind als Doppelbestimmungen aufgetragen: der Eichwert $10 \mu \mathrm{g} / 1$, der Eichwert $5 \mu \mathrm{g} / 1$, und der Meßwert im Serum. Die bei 50 Personen ohne erkennbare Krankheiten gemessenen Werte des Chromgehaltes im Serum sind in Abbildung 6 wiedergegeben. Aus der Abbildung geht hervor, daß die Verteilung des Chromgehaltes im Serum Gesunder als log-normal beschrieben werden kann, mit einem Median von $0,60 \mu \mathrm{g} / 1$.

Im vorliegenden Kollektiv zeigte das arithmetische Mittel des Chromgehaltes von Serum keinen signifikanten Unterschied $(\mathrm{p}>0,05)$ zwischen männlichen $(\overline{\mathrm{x}}=$ $0,69 \mu \mathrm{g} / 1 ; \mathrm{n}=35)$ und weiblichen $(\overline{\mathrm{x}}=0,81 \mu \mathrm{g} / 1 ; \mathrm{n}=15)$ Probanden.

Das Alter des untersuchten Kollektivs lag zwischen 18 und 53 Jahren, die gemessenen Serumchromwerte ließen
Tab. 3. Vorschrift für die flammenlose Atomabsorption

Element: Mangan

Matrix: Serum

1. Probenvorbehandlung: keine (Verwendung von Serum).

2. Geräte: 403 AAS oder 300 S AAS mit Deuteriumkompensator

2.1. Einstellungen : 403 AAS bzw. $300 \mathrm{~S}$ AAS

Wellenlänge $\quad: 279,5 \mathrm{~nm}$

HKL : PE Intensitron

Lampenstrom : 9 mAmpere

Für 403 AAS

Absorbance

Dämpfung

0,5 Ampere

1 (gilt auch für $300 \mathrm{~S}$ AAS)

2.2. Einstellungen : Graphitrohrküvette HGA 72

$\begin{array}{lllll}\text { Stufe I } & \text { : Trocknung } 1 & 60 \mathrm{~s} & 82^{\circ} \mathrm{C}\end{array}$

Stufe II $\quad$ : Trocknung $2 \quad 60 \mathrm{~s} \quad 118^{\circ} \mathrm{C}$

Temperaturprogramm: Rate 6 kontinuierlicher Temperaturanstieg bis $1020^{\circ} \mathrm{C}$ (Vorveraschung)

Stufe III : Endveraschung $90 \mathrm{~s} \quad 1300^{\circ} \mathrm{C}$

Stufe IV : Atomisierung $20 \mathrm{~s} \quad 2600^{\circ} \mathrm{C}$

2.3. Einstellungen : Schreiber

$10 \mathrm{mVolt}$ : Vollausschlag

Papiervorschub : $5 \mathrm{~s} / \mathrm{cm}$

3. Pipettiervolumen : $20 \mu \mathrm{l}$ Serum

4. Nachweisgrenze : $5 \mathrm{pg}(20 \mu \mathrm{l}$ einer Probe mit $0,25 \mu \mathrm{g} / \mathrm{l})$

5. Auswertung

Die Auswertung erfolgt von der Basislinie bei Atomisierungsbeginn bis zum Maximalwert. Eine zu starke Basisverschiebung während der Atomisierung wird durch eine Pappblende vor dem rechten Küvettenfenster vermieden.

6. Eichung

Die Eichung erfolgt durch Aufstockung der Serumprobe mit Mangankonzentrationen, die im Bereich der zu erwartenden Serumkonzentration liegen. Dabei soll das Serum höchstens um 10\% verdünnt werden. Empfohlene Eichwerte: 10, 5 und $1 \mu \mathrm{g} / \mathrm{l}$ Mangan 
keine Altersabhängigkeit erkennen. Die Präzision der Messungen innerhalb der gleichen Analysenserie wies einen Variationskoeffizienten von $13 \%$ auf. Bei der Bestimmung von Tag zu Tag erhöhte sich der Variationskoeffizient auf $16 \%$.

\section{Die Messung von Mangan (Mn) im Serum}

Die Bedingungen für die Messung von Mangan im Serum sind in Tabelle 3 wiedergegeben. Da die Mangan-Linie höhere Empfindlichkeit als die Chrom-Linie aufweist, können geringere Probenmengen von $20 \mu \mathrm{l}$ verwendet werden. Die höhere Empfindlichkeit der Mangan-Linie und die dadurch bedingte bessere Nachweisgrenze zur Mangan-Bestimmung gestattet es ferner, die Messungen unter Verwendung des Deuteriumkompensators durchzuführen. Dies ist im Fall des Mangan-Nachweises auch erforderlich, da Mangan bereits bei einer Temperatur von etwa $1320^{\circ} \mathrm{C}$ flüchtig wird. Bei der Veraschung dürfen also Temperaturen über $1300^{\circ} \mathrm{C}$ nicht verwendet werden, obwohl bei dieser Veraschungstemperatur die vollständige Vernichtung der organischen und anorganischen Matrix nicht sichergestellt ist. Die durch die nicht vollständig entfernte Matrix bedingten unspezifischen Signale werden jedoch durch den Deuteriumkompensator vom eigentlichen Meßvorgang ausgeschlossen.

Abbildung 4 zeigt die Optimierung der Veraschungstemperatur. Die günstigsten Bedingungen sind bei $1300^{\circ} \mathrm{C}$ erreicht. Im vorliegenden Beispiel ist bei dieser Temperatur die gesamte Matrix entfernt.

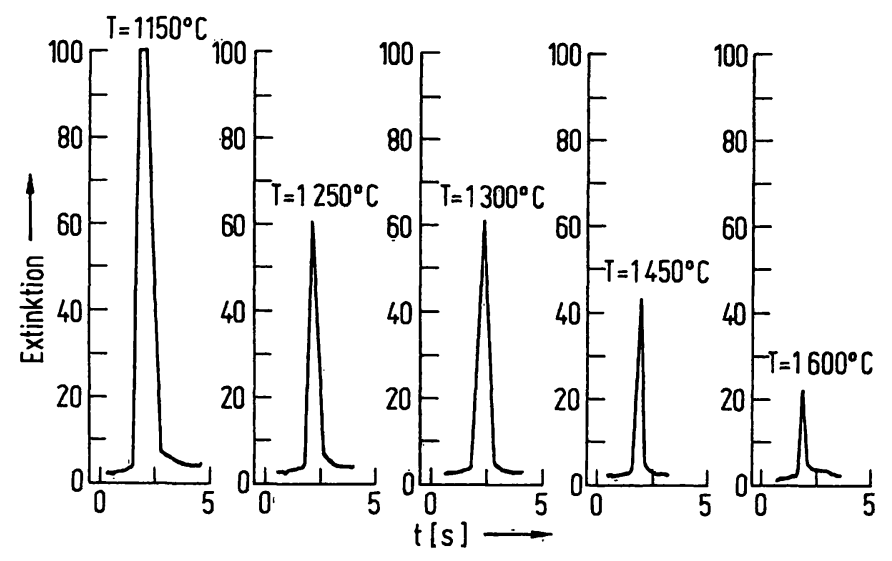

Abb. 4. Die Optimierung der Veraschungstemperatur für den Nachweis von Mangan im Serum mittels flammenloser Atomabsorptionsspektroskopie

Auf der Ordinate ist die Extinktion in willkürlichen Einheiten, auf der Abszisse die Zeit wiedergegeben.

Das Vorgehen entspricht den in Tabelle 3 gemachten Angaben, mit Ausnahme der Variation der Veraschungstemperatur. Bei Temperaturen unter $1250^{\circ} \mathrm{C}$ wird das erhaltene Signal von der Registrierapparatur nicht vollständig wiedergegeben. Das bei Temperaturen unter $1250^{\circ} \mathrm{C}$ erhaltene Signal ist hauptsächlich durch Rauch bedingt; durch Überlastung des Deuteriumkompensators konnte dieses unspezifische Signal nicht vollständig eliminiert werden. Bei einer Temperatur von $1450^{\circ} \mathrm{C}$ bzw. $1600^{\circ} \mathrm{C}$ nimmt das elementspezifische Signal ab, da bei dieser Temperatur Mangan bereits flüchtig wird. Der günstigste Temperaturbereich für die Veraschung beim Nachweis von Mangan im Serum dürfte demnach bei $1300^{\circ} \mathrm{C}$ liegen.
Die Optimierung der Atomisierungstemperatur zeigt Abbildung 5 . Die günstigsten Meßbedingungen sind bei einer Atomisierungstemperatur von $2600^{\circ} \mathrm{C}$ erreicht. Bei dieser Temperatur wird die höchste Ausbeute erzielt, die Eigenemission der Graphitrohrküvette muß allerdings durch Vorschalten einer Lochblende herabgesetzt werden.

Abbildung 6 zeigt bei 50 Personen ohne erkennbare Erkrankungen die Serum-Manganwerte, deren Verteilung als log-normal beschrieben werden kann, mit einem Median von $1,58 \mu \mathrm{g} / 1$.

In dem untersuchten Kollektiv zeigten die bei männlichen $(n=35)$ und weiblichen Probanden $(n=15)$ erhaltenen arithmetischen Mittelwerte des Serum-Mangange-

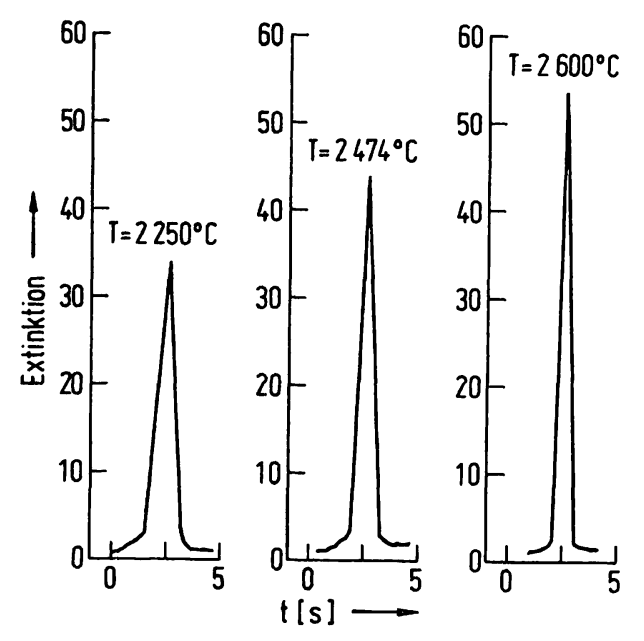

Abb. 5. Die Optimierung der Atomisierungstemperatur für den Nachweis von Mangan im Serum mittels flammenloser Atomabsorptionsspektroskopie

Auf der Ordinate ist die Extinktion in willkürlichen Einheiten, auf der Abszisse die Zeit wiedergegeben.

Das Vorgehen entspricht den in Tabelle 3 gemachten Angaben, mit Ausnahme der Atomisierungstemperatur. Mit zunehmender Atomisierungstemperatur ergeben sich höhere elementspezifische Extinktionswerte. Der günstigste Meßbereich dürfte bei einer Temperatur von $2600^{\circ} \mathrm{C}$ erreicht sein.

haltes mit Werten von $2,01 \mu \mathrm{g} / 1 \mathrm{bzw} .1,74 \mu \mathrm{g} / 1$ keinen statistisch signifikanten $(p>0,05)$ Unterschied. In dem untersuchten Altersbereich (18-53 Jahre) zeigten die Manganwerte im Serum keine Altersabhängigkeit.

Bei der Messung der Manganwerte im Serum innerhalb der Serie wurde ein Variationskoeffizient von $14 \%$ bei der Messung von Tag zu Tag ein Variationskoeffizient von $16 \%$ ermittelt.

\section{Diskussion}

Die Spurenelemente liegen im Serum in so geringem Gehalt vor, daß ihr atomabsorptionsspektrometrischer Nachweis nur mit hochempfindlichen Atomabsorptionsgeräten unter Verwendung einer Graphitrohrküvette gelingt. Bei Verwendung des Gerätes 290 AAS mit etwa 10-fach geringerer Nachweisgrenze lassen sich weder Chrom noch Mangan im Serum erfassen. Die Nachweisgrenze läßt sich 

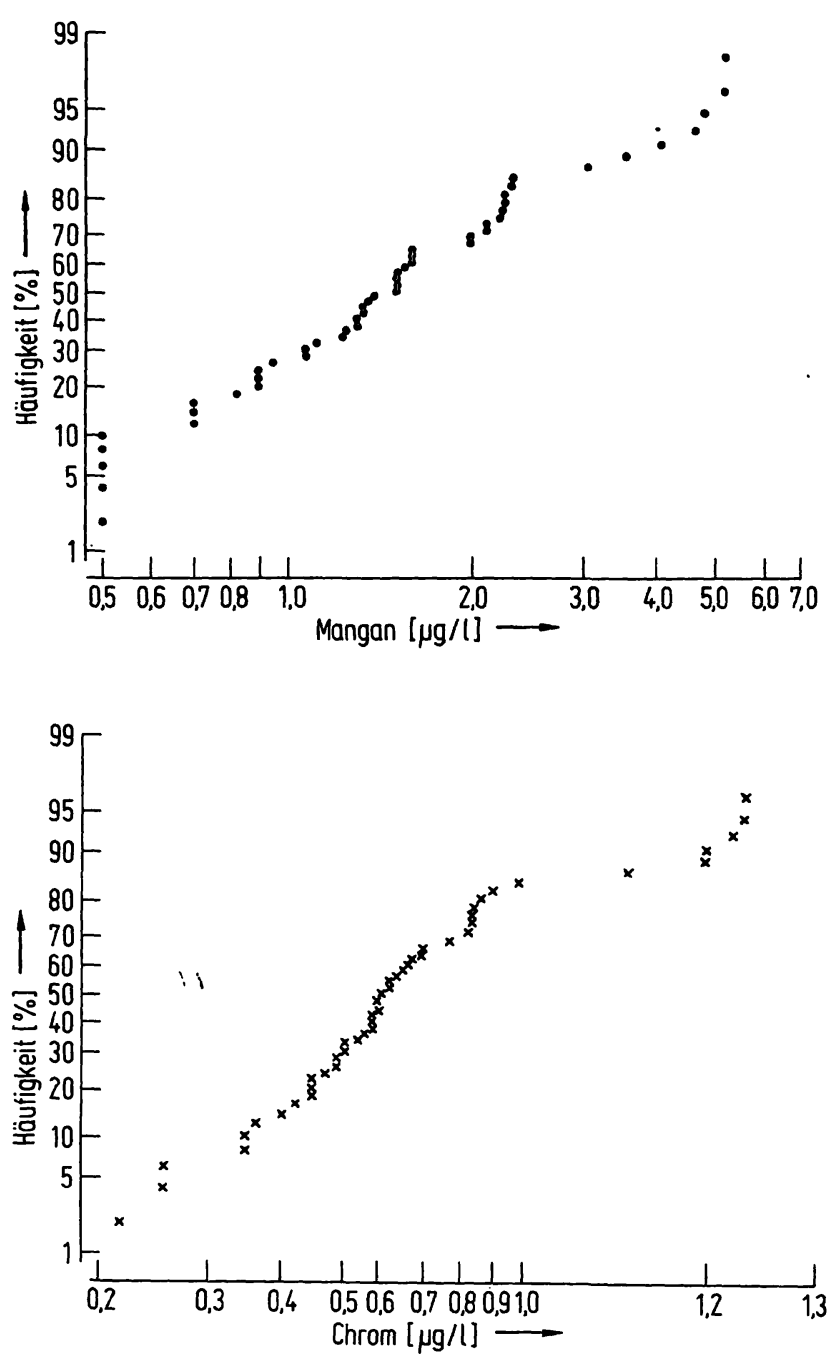

Abb. 6. Die im menschlichen Serum mittels flammenloser Atomabsorptionsspektroskopie ermittelten Werte von Chrom und Mangan bei 27 anscheinend gesunden Personen

Die Werte sind im Wahrscheinlichkeitsnetz nach Logarithmieren der Abszissengröße (Elektrolytgehalt im Serum) dargestellt.

Für beide Elemente findet sich für den Serumgehalt eine log-normale Verteilung.

praktisch auch nicht durch Einengen der Proben und Komplexierung der Elemente verbessern (Tab. 1).

Dies dürfte vor allem auf folgende Ursachen zurückzuführen sein:

1. Bei Verwendung von Reagenzien „pro analysi“" ist die Verunreinigung mit den zu messenden Spurenelementen in der Größenordnung des im Serum zu erwartenden Gehaltes, so daß nur die wenigen Reagenzien "Suprapur" verwendet werden können.

2. Die Einengung der Proben in der Hitze wurde in Glasgefäßen vorgenommen, an deren Wänden die Spurenelemente auf Grund der Polarität adsorbiert und somit dem Nachweis entzogen werden können.

3. Durch Enteiweißung mit anschließender Hitzeeinengung der Proben wird zwar die organische Matrix weitgehend entfernt, die im Serum vorhandenen anorganischen Substanzen bleiben jedoch zum großen Teil erhalten und können zu unspezifischen Signalen führen.

Die Atomabsorptionsgeräte 300 S AAS und 403 AAS unterscheiden sich in ihrer Empfindlichkeit nicht vom 290 AAS, die Nachweisgrenze ist jedoch bei diesen Geräten im Vergleich zum 290 AAS um etwa den Faktor 10 verbessert.

Die Nachweisgrenze (3) eines Elementes hängt außer vom verwendeten, Atomabsorptionsgerät auch von der Art der Graphitrohrküvette ab. Mit der stromregulierten HGA $72^{10}$ ) läßt sich die Nachweisgrenze für die meisten Spurenelemente im Serum im Vergleich zur HGA 70 um rund das 2-fache steigern: ${ }^{11}$ )

Bei Verwendung hochempfindlicher Atomabsorptionsgeräte (z. B. 300 S AAS oder 403 AAS) mit Graphitrohrküvette (z. B. HGA 72) kann die Serumprobe ohne vorherige chemische Aufbereitung in die Küvette gegeben werden. Durch den Verzicht auf eine chemische Vorbehandlung der Proben wird der Spurenelementgehalt weder durch Adsorption an Glaswände noch durch Zugabe nicht hochgradig reiner Chemikalien verändert. Bei der unmittelbaren Eingabe von Serum in die Küvette ist jedoch die Vermeidung unspezifischer Rauchsignale durch die Matrix von entscheidender Bedeutung.Die Vernichtung der Matrix gelingt im Fall von Chrom durch eine Veraschungstemperatur von $1400^{\circ} \mathrm{C}$. Diese hohe Temperatur kann jedoch bei Mangan nicht angewendet werden, da dieses Element $a b 1300^{\circ} \mathrm{C}$ flüchtig wird. Im Fall von Mangan müssen also eventuell auftretende unspezifische Signale durch die Anwendung des Deuteriumkompensators eliminiert werden.

Beim Trocknungs- und Veraschungsvorgang können gleichfalls Fehler beim Nachweis von Spurenelementen auftreten. Durch zu rasches Aufheizen kann die Probe in der Küvette verspritzt werden. Da aber in der Randzone der Küvette geringere Temperaturen erreicht werden als in der Mitte, ist es dann möglich, daß beim Veraschungsvorgang die Matrix nicht vollständig eliminiert wird und dadurch unspezifische Rauchsignale entstehen.

Die durch flammenlose Atomabsorption ermittelten Normwerte für den Chromgehalt des menschlichen Serums betragen: $0,6 \mu \mathrm{g} / 1$ (Median), bzw. $0,73 \mu \mathrm{g} / 1$ (arithmetisches Mittel).

Die Werte liegen somit in der gleichen Größenordnung wie die geringsten von Mertz et al (4) mittels Emissionsspektralanalyse erhaltenen Resultate. Die mittels flammenloser Atomabsorption erhaltenen Werte für den

\footnotetext{
19 Bei Verwendung der HGA 72 zur Messung von Spurenelementen im Serum sollte jedoch auf die Spezialrohre, die vor allem für die Messung in wäßrigen Lösungen konzipiert sind, verzichtet werden, da sich in den Winkeln und Ecken des Spezialrohres organische Rückstände ansammeln, die mit weiter zugegebenen Chrom- und Manganionen Carbide bilden können. Die Chrom- und Manganionen vermögen sich so dem Nachweis zum Teil zu entziehen.

11) unveröffentlichte Befunde
} 
Chromgehalt des menschlichen Serums sind deutlich geringer als die mittels Neutronenaktivierungsanalyse erhaltenen Resultate, wobei für diese Diskrepanz keine sichere Deutung gegeben werden kann.

Der mittels flammenloser Atomabsorption gemessene Serumgehalt an Chrom weist Extremwerte von 0,23$1,90 \mu \mathrm{g} / 1$ auf, bei der Verwendung der Emissionsspektralanalyse betrug demgegenüber der Extrembereich 1,1$80,0 \mu \mathrm{g} / \mathrm{l}$. Für die Neutronenaktivierungsanalyse geben $K$. Kasperek et al (5) eine einfache Standardabweichung für die Serum-Chromwerte von 5,6 $\mathrm{g} / \mathrm{l}$ an. Angegeben als Variations-Koeffizient betrug die Präzision für die Messung des Chromgehaltes von Serum in der Serie 13\% und für die Präzision von Tag zu Tag $16 \%$.

Für den Mangangehalt von Serum wurden mit der flammenlosen Atomabsorption ein Median von 1,58 $\mu \mathrm{g} / 1$ und

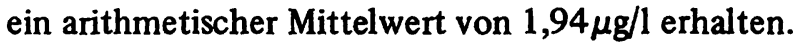
Mittels Neutronenaktivierungsanalyse fanden $P$. Papavasiliou und G. Cotzias (6) einen Mangangehalt im Serum von $2,5 \mu \mathrm{g} / 1$. Dieser Wert stimmt mit den mittels flammenloser Atomabsorption erhaltenen Resultaten sehr gut überein. Mit der flammenlosen Atomabsorption betragen die Extremwerte für den Mangangehalt im Serum 0,50-7,89 $\mu \mathrm{g} / 1$. Demgegenüber wurden mittels Emissions- spektralanalyse nach vorheriger Elementanreicherung $0,5-210,0 \mu \mathrm{g} / 1$ gefunden (4). Im Vergleich zu den bisher mitgeteilten Verfahren zur Messung von Spurenelementen im Serum weist also die flammenlose Atomabsorption einen relativ geringen Streubereich auf, sowohl bei der Messung in der Serie als auch bei der Messung von Tag zu Tag.

Die Richtigkeit der Messung ergibt sich theoretisch aus der elementspezifischen Atomabsorption (1), praktisch läßt sie sich in Anbetracht der geringen Serumkonzentrationen nur durch Aufstockungsversuche belegen, wie $s_{i} e$ in Abbildung 3 am Beispiel des Chroms dargestellt sind. Im Falle des Mangans konnten entsprechende Ergebnisse belegt werden.

Die flammenlose Atomabsorption weist demnach für die Messung von Spurenelementen folgende Vorteile auf:

1. Die Methode ist einfach durchführbar

2. Der apparative Aufwand ist vertretbar

3. Die Meßergebnisse sind elementspezifisch

4. Der Arbeitsaufwand ist mit 7-8 Minuten je Analyse relativ gering

5. Für die Messung werden geringe Blutmengen benötigt (kleiner als $2 \mathrm{ml}$ )

6. Die Ergebnisse sind gut reproduzierbar.
1. Welz, B. (1973) Atomabsorptionsspektroskopie, Verlag Chemie, Heidelberg

2. Buttgereit, G. (1972), Arbeitsmedizin, Sozialmedizin, Arbeitshygiene 10, 286-292

3. Paschen, K \& Spieckermanni, P. G. (1970), Deut. Med. Wochenschr. 95, 2577-2581

4. Mertz, D. P., Koscl.nick, R., Wilk, G., \& Pfeilsticker, K. (1968), diese Z. 6, 171-174
5. Kasperek, K., Schicha, H., Siller, V., Feinendegen, L. E. \& Höck, A. (1972) Trace element corcentrations in human serum; diagnostic implications, presented at I.A.E.A. Symposium on Nuclear Activations Techniques in the Life Sciences IAEA/SM-157 Bled, Yugoslavia

6. Papavasiliou, P. S. \& Cotzias, G. (1961), J. Biol. Chem. 236, 2365-2369
Prof. Dr. W. Kübler

Klin. Anstalten d. Univ. 4 Düsseldorf 1

Moorenstr. 5 